\title{
Associations between Intake of Folate, Methionine, and Vitamins B-12, B-6 and Prostate Cancer Risk in American Veterans
}

\author{
Adriana C. Vidal, ${ }^{1}$ Delores J. Grant, ${ }^{2}$ Christina D. Williams, ${ }^{3}$ Elizabeth Masko,,${ }^{4,5}$ \\ Emma H. Allott, ${ }^{6}$ Kathryn Shuler, ${ }^{4,5}$ Megan McPhail, ${ }^{7}$ Alexis Gaines, ${ }^{7}$ Elizabeth Calloway, ${ }^{4,5}$ \\ Leah Gerber, ${ }^{7}$ Jen-Tsan Chi, ${ }^{8}$ Stephen J. Freedland, ${ }^{5,7,9}$ and Cathrine Hoyo, 10 \\ ${ }^{1}$ Department of Obstetrics and Gynecology and Program of Cancer Detection, Prevention and Control, Duke University School of \\ Medicine, Durham, NC 27710, USA \\ ${ }^{2}$ Department of Biology and Cancer Research Program, JLC-Biomedical/Biotechnology Research Institute, North Carolina Central \\ University, Durham, NC 27707, USA \\ ${ }^{3}$ Center for Health Services Research in Primary Care and Department of Hematology/Oncology, Durham VA Medical Center, \\ Durham, NC 27705, USA \\ ${ }^{4}$ Division of Urology, Department of Surgery, Duke University Medical Center, Durham, NC 27710, USA \\ ${ }^{5}$ Department of Surgery, Durham VA Medical Center, Durham, NC 27705, USA \\ ${ }^{6}$ Department of Community and Family Medicine and Program of Cancer Detection, Prevention and Control, Duke University \\ School of Medicine, Durham, NC 27710, USA \\ ${ }^{7}$ Duke Prostate Center, Division of Urology, Department of Surgery, Duke University Medical Center, Durham, NC 27710, USA \\ ${ }^{8}$ Institute for Genome Sciences \& Policy and Department of Molecular Genetics \& Microbiology, Duke University Medical Center, \\ Durham, NC 27708, USA \\ ${ }^{9}$ Department of Pathology, Duke University Medical Center, Durham, NC 27710, USA \\ ${ }^{10}$ Department of Community and Family Medicine, Duke University School of Medicine, P.O. Box 104006, Durham, NC 27710, USA
}

Correspondence should be addressed to Cathrine Hoyo, cathrine.hoyo@duke.edu

Received 24 April 2012; Revised 17 June 2012; Accepted 21 June 2012

Academic Editor: T. L. Vaughan

Copyright ( $\odot 2012$ Adriana C. Vidal et al. This is an open access article distributed under the Creative Commons Attribution License, which permits unrestricted use, distribution, and reproduction in any medium, provided the original work is properly cited.

\begin{abstract}
Prostate cancer (PC) is the second leading cause of cancer death in men. Recent reports suggest that excess of nutrients involved in the one-carbon metabolism pathway increases PC risk; however, empirical data are lacking. Veteran American men (272 controls and 144 PC cases) who attended the Durham Veteran American Medical Center between 2004-2009 were enrolled into a casecontrol study. Intake of folate, vitamin B12, B6, and methionine were measured using a food frequency questionnaire. Regression models were used to evaluate the association among one-carbon cycle nutrients, MTHFR genetic variants, and prostate cancer. Higher dietary methionine intake was associated with $\mathrm{PC}$ risk $(\mathrm{OR}=2.1$; 95\%CI 1.1-3.9) The risk was most pronounced in men with Gleason sum $<7(\mathrm{OR}=2.75 ; 95 \% \mathrm{CI} 1.32-5.73)$. The association of higher methionine intake and PC risk was only apparent in men who carried at least one MTHFR A1298C allele $(\mathrm{OR}=6.7 ; 95 \% \mathrm{CI}=1.6-27.8)$, compared to MTHFR A1298A noncarrier men $(\mathrm{OR}=0.9 ; 95 \% \mathrm{CI}=0.24-3.92)$ ( $\mathrm{p}$-interaction $=0.045)$. There was no evidence for associations between $\mathrm{B}$ vitamins (folate, B12, and B6) and PC risk. Our results suggest that carrying the MTHFR A1298C variants modifies the association between high methionine intake and PC risk. Larger studies are required to validate these findings.
\end{abstract}

\section{Introduction}

Prostate cancer (PC) is the most commonly diagnosed malignancy in men, and the second leading cause of cancer death in men globally [1]. Age adjusted PC incidence and mortality exhibits considerable geographic and racial variation, suggesting that both heritable and environmentally acquired/dietary factors are important $[2,3]$. Regarding dietary factors, either deficiencies or excesses of nutrients involved in the one-carbon metabolism pathway have been hypothesized to increase PC risk, but findings are inconsistent [4-15]. The one-carbon cycle is necessary for both 


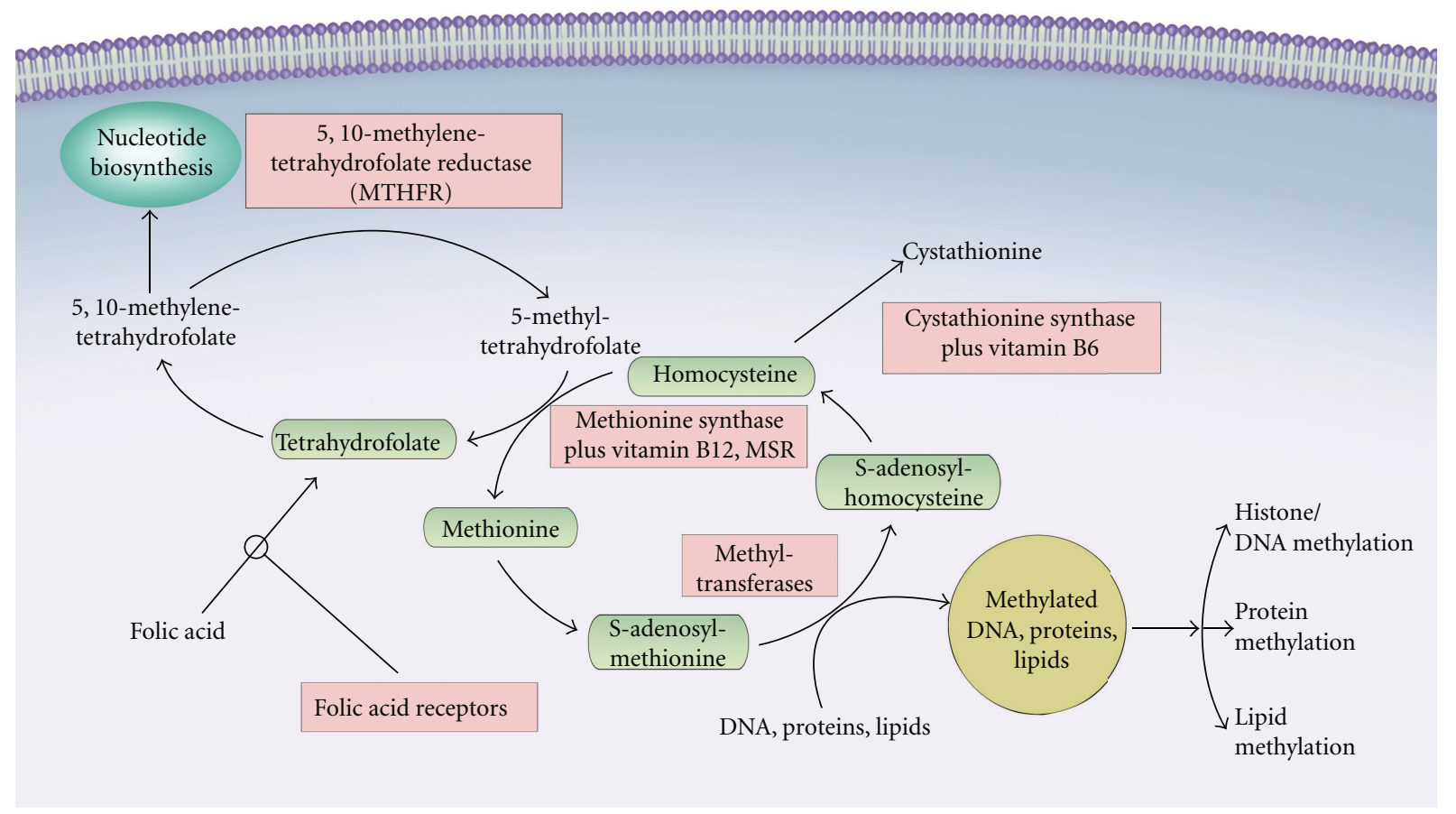

FIGURE 1: A simplified representation of the one-carbon metabolism pathway.

cellular proliferation and epigenetic modification and folate is a critical component of this pathway. Folate functions as an important source of carbon moieties in the synthesis of nucleotides that are essential for DNA repair and replication. The important role of folate is illustrated by the mutations and chromosomal damage associated with its deficiency. These effects are central to the efficacy of antifolate chemotherapeutic agents (e.g., methotrexate) as tumor therapeutics. Folate is also essential in the conversion of methionine to its derivative, S-adenosylmethionine, the principal methyl donor [16], which transfers methyl groups to molecules key for several processes, including DNA synthesis and repair [17]. The predominant form of folate in circulation is 5-methylenehydrofolate (5-methyl THF), which becomes available when methylenetetrahydrofolate reductase (MTHFR) converts 5,10-methyl THF to 5-methyl THF [18]. This latter form of folate (5-methyl THF) is essential in the remethylation of homocysteine to methionine, a reaction catalyzed by vitamin B12 (Figure 1). Furthermore, 5,10-methylenehydrofolate promotes the synthesis of thymidylate from uracil minimizing the misincorporation of uracil into DNA, which could play a protective role in cancer development [19].

Numerous tumor tissues, including PC, show a general pattern of global DNA hypomethylation and gene-specific hypermethylation [20], suggesting one carbon-cycle deficiency or excess may play a role in tumor development or progression. Low folate levels, whether measured in the usual diet [21-23] or in circulation [24], have been previously associated with higher risk of breast, lung, pancreatic, and colorectal cancer, and high folate levels have been associated with lower risk of some [23], but not all cancers [8, $25,26]$. However, more recent studies [7] have reported elevated PC risk in relation to high plasma folate levels, while dietary folate [4] was associated with lower PC risk; yet others $[6,9]$ found no association between circulating concentrations of folate and PC risk in Europe and in USA. These inconsistencies in findings may be due to genetic or nutritional differences inherent in the two populations $[23,27,28]$. Some $[29,30]$ have hypothesized that part of the increase in incidence in many adenocarcinomas over the past several years is, in part, due to excessive folate resulting from fortification of milled grain in Western countries, which in USA. and Canada occurred in 1998 [31]. These inconsistent findings could also be due to assessment of single nutrients in this pathway, not taking into account their synergistic functional interaction with other nutrients. Disentangling these relationships will improve our understanding of potential mechanisms underlying these methyl group donor nutrients and PC, ultimately guiding prevention efforts. Herein, we evaluated whether upper intake levels of key nutrients in the one-carbon cycle: folate, vitamins B12, B6, and methionine, are associated with increased PC risk among Black and White American veterans. To glean mechanistic insights into these associations, we further examined the extent to which genetic variants of the MTHFR gene [32] modify the association between nutrient intake and PC risk.

\section{Material and Methods}

2.1. Study Design and Participants. Data collection methods have been described elsewhere [33, 34]. Men who had been screened for PC with a serum PSA in the last 12 months were recruited to participate in an ongoing case-control study at the Durham Veterans Affairs Medical Center (DVAMC) in Durham, NC, from January 2007 to November 2009. All 
subjects were at least 18 years old and had no history of prostate cancer. Cases were new patients with biopsy-positive prostate cancer who were scheduled for a prostate needle biopsy at the urology clinic at the DVAMC, due to elevated PSA and/or abnormal rectal examination. Of the 485 patients scheduled for a biopsy, 420 had the biopsy done and 166 of these had biopsy-positive prostate cancer. Analyses for the present study were restricted to patients who completed the dietary questionnaire $(N=144)$, a participation rate of $86.7 \%$ (144/166). Controls were patients identified through the outpatient urology and primary care clinics at the DVAMC (the same center from which cases were recruited) and had not been recommended for a prostate needle biopsy. Conditions for which these patients were seen were not associated with intake of folate or other one-carbon nutrients. These nonhospitalized patients referred to these clinics were eligible for enrollment regardless of the reason for referral. Controls also had to have no history of PC and had a PSA test within one year of enrollment into the study. Controls were not diagnosed with diseases associated with intake of folate nor other one-carbon nutrients. Of the 421 eligible controls, 272 completed the dietary questionnaire, yielding a $64.5 \%(272 / 421)$ participation rate. This study was approved by the Duke University and DVAMC Institutional Review Boards and all patients signed a written consent form.

2.2. Data Collection. Trained interviewers collected questionnaire data, obtained anthropometric measurements (weight and height), and abstracted medical records. Weight was measured using a digital scale, and a stadiometer was used to measure height [35]. These measurements were used to calculate body mass index (BMI), defined as weight (in kilograms) divided by the square of height (in meters squared). All questionnaires were self-administered and typically filled out the day of the scheduled clinic visit or returned shortly thereafter by mail prior to the patient knowing the outcome of their biopsy. Risk factor questionnaires queried information on sociodemographic characteristics, lifestyle factors such as smoking and alcohol use, medication use, and family history of PC.

Dietary information was obtained using the Harvard food frequency questionnaire (FFQ), developed and tested by [36]. This 61-item food frequency questionnaire assessed the frequency of consumption according to prespecified portion sizes for each food and beverage item. Subjects reported their intake in the past 12 months, and this time period was selected to account for seasonal variation in consumption. Daily food, nutrient, and total energy intakes were determined using the reported frequency of consumption and portion sizes. The nutrients of interest for this study were one carbon cycle nutrients measurable in FFQs: folate, vitamin B6, vitamin B12, and methionine. Nutrient intake for each food item was computed by multiplying the relative frequency of consumption by the nutrient content of the prespecified portion size using USDA food composition sources [37] and data from manufacturers [38, 39]. Nutrient intake also incorporated reported supplementation. Folic acid is added to fortified foods in USA, and natural foods containing these vitamins were also measured and included in the estimates.

2.3. DNA Sample Preparation and Genotyping. DNA was isolated from peripheral blood by standard DNA isolation (Qiagen Inc., Valencia, CA, USA) and quantified by ultraviolet spectrophotometry. Prior to genotyping, DNA concentration was determined using PicoGreen assay (Life Technologies, Gaithersburg, MD) and measured using the fluorescence intensity measurements plotted against a standard curve that was generated from the average fluorescence intensity of standards run in replicate. Based on the PicoGreen quantification, $10 \mathrm{ng}$ of genomic DNA from each sample was used in the iPlex assay for Sequenom-iPlex Genotyping (Sequenom Inc, San Diego, CA).

The Sequenom MassArray Platform (Sequenom Inc, San Diego, CA) was used to assay for MTHRF variants rs 1801133 and rs1801131. Sequenom online assay tools (Assay Designer 4.0) were used to design the iPlex assay for the variants as part of a multiplex reaction to query 16 different SNPs. The data were analyzed by Sequenom-Typer 4.0 software. The Sequenom-iPlex genotyping and analysis was validated with CEPH gDNA controls by performing the iPlex assay and scanning on the MALDI-TOF Mass Spectrometer. The genotyping and analysis was performed at the David $\mathrm{H}$. Murdock Research Institute (DHMRI) Genomics Laboratory (Kannapolis, NC). At the time of this analysis, 364 samples were submitted and 358 successfully produced good spectra for genotyping at a failure rate of $<2.2 \%$. The Post-QC (Call Rate) of MTHRF variants rs1801133 and rs1801131 was $99.70 \%$.

2.4. Statistical Analyses. Our hypothesis was to examine whether higher than recommended intake of one carbon nutrients was associated with PC risk and whether this association was similar in low-grade versus high-grade PC. Low-grade PC was defined as Gleason sum $<7$ and highgrade was defined as Gleason $\geq 7$. Nutrient intake derived from FFQs was estimated for 4 one carbon cycle nutrients, and then dichotomized as either high if the nutrient intake was at above the recommended upper limit, or low, which included normal and below the recommended levels. Cut-offs for folate, vitamins B-6, B-12, and methionine were made at higher than recommended dietary allowance (RDA) by the Food and Nutrition Board (FNB) and the Institute of Medicine (IOM). High folate was $>700 \mathrm{mcg} / \mathrm{day}$ (recommended is $400 \mathrm{mcg} /$ day), high vitamin B12 was $>25 \mathrm{mcg} /$ day (recommended is $2.4 \mathrm{mcg} /$ day), high vitamin B6 was $>4.5 \mathrm{mg} /$ day (recommended is $1.7 \mathrm{mg} /$ day), and high methionine was $>2.6 \mathrm{~g} /$ day (based on a US standard diet of 50-100 g protein/day, which would render $1.5-3.0 \mathrm{~g} /$ day of methionine, Dr. Scornik at Dartmouth College, personal communication).

Potential confounders (age, height, and BMI) were normally distributed overall and were treated as continuous variables in modeling. Race was self-reported and categorized as African American, White, and other (Native American and Latino). Family history included was maternal 
TABLE 1: Risk factor characteristics for prostate cancer participants.

\begin{tabular}{|c|c|c|}
\hline Risk factor & $\begin{array}{c}\text { Cases } n=144 \\
n(\%) \\
\text { Mean }(\mathrm{SD})\end{array}$ & $\begin{array}{c}\text { Controls } n=272 \\
n(\%) \\
\text { Mean }(\mathrm{SD})\end{array}$ \\
\hline Age & $63.12(5.62)$ & $61.77(7.46) P=0.06$ \\
\hline Height (in.) & $69.63(2.68)$ & $69.83(2.89) P=0.51$ \\
\hline Obesity (BMI) & $29.39(5.51)$ & $30.74(5.64) P=0.02$ \\
\hline Race & & $P=0.0002$ \\
\hline African American & $78(54.55)$ & $92(33.95)$ \\
\hline Caucasian & $64(44.76)$ & $174(64.21)$ \\
\hline Other & $1(0.70)$ & $5(1.85)$ \\
\hline Family history PC & & $P=0.0072$ \\
\hline Yes & $34(23.61)$ & $36(13.24)$ \\
\hline No & $110(76.39)$ & $236(86.76)$ \\
\hline Drinking status & & $P=0.5547$ \\
\hline Current drinker & $62(43.06)$ & $109(40.07)$ \\
\hline Former drinker & $80(55.56)$ & $155(56.99)$ \\
\hline Never drinker & $2(1.39)$ & $8(2.94)$ \\
\hline Tobacco use & & $P=0.0017$ \\
\hline Current smoker & $47(32.64)$ & $61(22.43)$ \\
\hline Former smoker & $96(66.67)$ & $200(73.53)$ \\
\hline Never smoker & $1(0.69)$ & $11(4.04)$ \\
\hline $\begin{array}{l}\text { Gleason < } 7 \\
\text { (44 Black/33 White) }\end{array}$ & $76(53.15)$ & NA \\
\hline $\begin{array}{l}\text { Score } \geq 7 \\
(37 \text { Black/31White) }\end{array}$ & $67(46.85)$ & \\
\hline
\end{tabular}

lineage (maternal uncle) or paternal lineage (father, brother, or paternal uncle) (yes or no) and these combined. Data on drinking and smoking were also self-reported and categorized into current, former, and never categories.

Descriptive statistics (means, SD) and percentages for cases and controls were used to compare using $X^{2}$ tests for categorical variables and Wilcoxon rank sum test for continuous variables. Means and standard deviations for Bvitamins and methionine were compared between $\mathrm{PC}$ cases and controls and between MTHFR genotypes. Unconditional logistic regression was used to estimate the odd ratios (ORs) and 95\% confidence intervals (95\%CI)-for the association between high nutrient intake, genotypes, and PC risk. Multinomial analyses were used for low-grade and high-grade PC, using no-cancer as reference. Confounders adjusted for in all models were age, race, family history of PC, BMI, and smoking and drinking status, which are confounders in the population and in this population. All analyses were done using SAS version 9.2 (SAS Institute, Inc., Cary, NC).

\section{Results}

The clinical characteristics of the study participants are described in Table 1 . PC cases $(n=144)$ and controls $(n=$ 272) were comparable in age $(P=0.06)$ and height $(P=$ 0.51). Controls (mean BMI $=30.74, \mathrm{SD}=5.64)$, however, had higher BMI than cases (mean BMI $=29.39, \mathrm{SD}=5.51$,
$P=0.02)$. African Americans comprised 55\% of the cases but only $34 \%$ of the controls $(P=0.0002)$. A family history of PC was present for $24 \%$ of the cases, versus $13 \%$ in the controls $(P=0.0072)$. Both cases and controls were either current or former smokers $(P=0.002)$. Low-grade disease was found in $53 \%$ of cases.

Table 2 shows the associations between folate, vitamins $\mathrm{B} 6, \mathrm{~B} 12$, and methionine intake in controls and PC cases, the latter further stratified into high grade (Gleason $\geq 7$ ) and low grade (Gleason $<7$ ). Compared to men reporting lower intake $\leq 700 \mathrm{mcg} /$ day, those reporting higher folate intake had similar overall PC risk (OR $=1.02$, 95\%CI $0.63-$ 1.64) after adjusting for potential confounders. Although neither risk estimate reached statistical significance, when cases were stratified into low and high grade, there was an inverse association between high folate intake and high-grade $\mathrm{PC}(\mathrm{OR}=0.68,95 \% \mathrm{CI} 0.35-1.34)$ and a positive association with low-grade disease $(\mathrm{OR}=1.42,95 \% \mathrm{CI}=0.81-2.47)$. Similar patterns of association were observed when vitamin B6 intake was evaluated. In contrast, high vitamin B12 intake associations with both HG PC and LG PC were not statistically significant. The only significant observation was that high intake of methionine was associated with increased PC risk $(\mathrm{OR}=2.1,95 \% \mathrm{CI} 1.1-3.9, P=0.02)$, when compared to intake $\leq 2.6 \mathrm{~g} /$ day. These associations were somewhat stronger for low-grade $\mathrm{PC}(\mathrm{OR}=2.8,95 \% \mathrm{CI} 1.3-$ 5.7, $P=0.007)$. While of lower magnitude than for lowgrade disease, these associations were in a similar direction for high-grade disease $(\mathrm{OR}=1.44,95 \% \mathrm{CI} 0.58-3.54, P=$ 0.43 ). These patterns of association were similar in African Americans and Whites (data not shown).

We explored whether PC risk varied by common MTHFR polymorphisms (Table 3). The frequency of these genotypes in controls were similar to those in HapMap where minor allele frequency (TT) was $8 \%$ and CT frequency was $31 \%$ for $677 \mathrm{CT}$, and minor allele frequency (CC) was 7\% and AC frequency was $37 \%$ for the 1298 SNP. In PC cases, $66 \%$ were homozygous for the MTHFR C677T wild-type allele "CC", versus 35\% that carried either 677CT (24\%) or 677TT (11\%). In controls, 54\% were homozygous for the C677T wild-type allele (CC), and 46\% were either homozygous (TT: 37\%) or heterozygous (CT: $9 \%$ ) carriers of the MTHFR variant; these variants were in $\operatorname{HWE}(P=0.27)$. Sixtysix percent of PC cases were wild type for the A1298C variant, and 35\% carried the heterozygous (1298AC: $31 \%$ ) or homozygous (1298CC: 4\%) variant. Fifty-three percent of the controls were homozygous for the A1298C wild-type allele (AA), and 47\% were either homozygous (CC: $6 \%$ ) or heterozygous (CA: $41 \%$ ) carriers of the MTHFR variant, and they did not deviate from $\operatorname{HWE}(P=0.41)$. We observed no significant association between carrying the MTHFR C677T $(\mathrm{OR}=0.7,95 \%$ CI $0.3-1.3)$ or MTHFR A1298C $(\mathrm{OR}=0.70$, 95\% CI 0.37-1.33, $P=0.28$ ) and PC risk (Table 3 ).

To further evaluate the interaction of high methionine intake and PC risk association by MTHFR genotypes, we measure $\mathrm{OR}$ and $95 \% \mathrm{CI}$ in PC cases. The association between higher methionine intake and $\mathrm{PC}$ risk did not vary significantly by MTHFR C677T genotype (Table 4). However, we observed considerable variation between methionine 
TABLE 2: Folate, vitamins B6, B12, and methionine intake* in total PC, HG, and LG cases and controls.

\begin{tabular}{|c|c|c|c|c|}
\hline Nutrient & $\begin{array}{l}\text { Controls } \\
n=272\end{array}$ & $\begin{array}{c}\text { Total PC } \\
n=144 \\
\mathrm{OR}^{* *}(95 \% \mathrm{CI}), P \text { value }\end{array}$ & $\begin{array}{c}\text { HG PC } \\
n=68 \\
\mathrm{OR}^{* *}(95 \% \mathrm{CI}), P \text { value }\end{array}$ & $\begin{array}{c}\text { LG PC } \\
n=77 \\
\mathrm{OR}^{* *}(95 \% \mathrm{CI}), P \text { value } \\
\end{array}$ \\
\hline \multicolumn{5}{|l|}{ Folate } \\
\hline Low/normal ( $\leq 700 \mathrm{mcg} /$ day $)$ & 188 & 102 & 54 & 49 \\
\hline \multirow[t]{3}{*}{ High (>700 mcg/day) } & 84 & 42 & 14 & 28 \\
\hline & & 1.02 (95\%CI; 0.64-1.63) & 0.68 (95\%CI; 0.35-1.34) & 1.42 (95\%CI; 0.81-2.47) \\
\hline & & $P=0.95$ & $P=0.26$ & $P=0.21$ \\
\hline \multicolumn{5}{|l|}{ B6 } \\
\hline Low/normal ( $\leq 4.5 \mathrm{mg} /$ day $)$ & 206 & 113 & 57 & 57 \\
\hline \multirow[t]{3}{*}{$\operatorname{High}(>4.5 \mathrm{mg} /$ day $)$} & 66 & 31 & 11 & 20 \\
\hline & & 0.92 (95\%CI; 0.55-1.54) & 0.65 (95\%CI; 0.31-1.33) & $1.24(95 \% \mathrm{CI} ; 0.67-2.7)$ \\
\hline & & $P=0.76$ & $P=0.22$ & $P=0.48$ \\
\hline \multicolumn{5}{|l|}{ B12 } \\
\hline Low/normal ( $\leq 25 \mathrm{mcg} /$ day $)$ & 209 & 107 & 52 & 56 \\
\hline \multirow[t]{3}{*}{ High (>25 mcg/day) } & 63 & 37 & 16 & 21 \\
\hline & & 1.29 (95\%CI; 0.78-2.12) & 1.12 (95\%CI; 0.56-2.16) & $1.38(95 \% \mathrm{CI} ; 0.74-2.5)$ \\
\hline & & $P=0.32$ & $P=0.77$ & $P=0.31$ \\
\hline \multicolumn{5}{|l|}{ Methionine } \\
\hline Low/normal ( $\leq 2.6 \mathrm{~g} /$ day $)$ & 249 & 119 & 60 & 60 \\
\hline \multirow[t]{3}{*}{$\operatorname{High}(>2.6 \mathrm{~g} /$ day $)$} & 23 & 25 & 8 & 17 \\
\hline & & 2.08 (95\%CI; 1.10-3.90) & $1.44(95 \% \mathrm{CI} ; 0.58-3.54)$ & 2.75 (95\%CI; 1.32-5.73) \\
\hline & & $P=0.02$ & $P=0.43$ & $P=0.007$ \\
\hline
\end{tabular}

* Adjusted for age, race, family history of PC, BMI, and smoking status.

** Referents are subjects in the low intake group of each nutrient of interest.

PC: prostate cancer.

HG PC: high grade (Gleason $\geq 7$ ).

LG PC: low grade (Gleason $<7$ ).

TABLE 3: ORs and 95\%CI for the association between MTHFR gene polymorphisms* and PC risk.

\begin{tabular}{lccc}
\hline & $\begin{array}{c}\text { PC cases } n=55 \\
\text { Frequency }(\%)\end{array}$ & $\begin{array}{c}\text { Controls } n=192 \\
\text { Frequency }(\%)\end{array}$ & OR (95\%CI), P value \\
\hline $\begin{array}{l}\text { MTHFR polymorphism C677T } \\
\text { CC (homo wild type) }\end{array}$ & $36(65.45)$ & $103(53.65)$ & 1.0 \\
CT (hetero) and TT (homo) & $19(34.55)$ & $89(46.35)$ & $0.67(0.34-1.31), P=0.23$ \\
MTHFR polymorphism A1298C & & $103(53.37)$ & 1.0 \\
AA (homo wild type) & $36(65.45)$ & $90(46.63)$ & $0.70(0.37-1.33), P=0.28$ \\
AC (hetero) and CC (homo) & $19(34.55)$ & & \\
\hline
\end{tabular}

* Adjusted for age, race, BMI, and smoking status.

intake and PC risk in carriers of MTHFR A1298C (OR = $6.7,95 \%$ CI 1.6-27.8) compared to noncarriers $(\mathrm{OR}=1.0$, $95 \% \mathrm{CI}=0.2-3.9)$. The cross-product term for MTHFR A1298C and methionine was statistically significant $(P=$ 0.045). Thus, high methionine intake association with $P C$ risk seems to be linked to the MTHFR A1298C polymorphism in this population.

\section{Discussion}

Our key findings were that high intake of methionine, which after its conversion to S-adenosylmethionine becomes the principal methyl donor for DNA methylation, was associated with higher overall risk of $\mathrm{PC}$ and that association was only evident in men with carriers of the MTHFR A1298C genotype. These associations remained essentially unchanged when analyses were restricted to African Americans or Whites. Associations between B vitamins and PC risk were unremarkable and inconsistent and not modified by MTHFR genotypes. Our findings are consistent with the hypothesis that excessive intake of a key one-carbon cycle nutrient may be associated with PC risk, particularly in carriers of the MTHFR A1298C genotype. This increased PC risk is possibly due to acceleration of growth of preexisting neoplasms [40], though these results require validation in other and larger datasets. 
TABLE 4: ORs and 95\%CI for the association between methionine intake and PC risk in carriers and noncarriers of C677T and A1298C MTHFR gene polymorphisms*.

\begin{tabular}{lccc}
\hline & $\begin{array}{c}\text { PC cases } n=55 \\
\text { Frequency }(\%)\end{array}$ & $\begin{array}{c}\text { Controls } n=192 \\
\text { Frequency }(\%)\end{array}$ & OR (95\%CI), $P$ value \\
\hline $\begin{array}{l}\text { Methionine }>\text { 2.6 g/day in } \\
\text { MTHFR polymorphism C677T carriers }\end{array}$ & $36(65.45)$ & $103(53.65)$ & OR $=1.96(0.59-6.41), P=0.26$ \\
CC (homo wild type) & $19(34.55)$ & $89(46.35)$ & OR $=2.93(0.7-12.24), P=0.14$ \\
CT (hetero) and TT (homo) & & & \\
\hline Methionine $>$ 2.6 g/day in & & $103(53.37)$ & OR $=0.97(0.24-3.92), P=0.97$ \\
MTHFR polymorphism A1298C carriers & $36(65.45)$ & $90(46.63)$ & OR $=6.67(1.59-27.83), P=0.01$ \\
AA (homo wild type) & $19(34.55)$ & & \\
AC (hetero) and CC (homo)
\end{tabular}

* Adjusted for age, race, BMI, and smoking status.

Mechanisms by which higher methionine intake could increase PC risk remain speculative. Although these results could have been due to chance alone, methionine is the key player in the one-carbon metabolism cycle as after conversion to S-adenosylmethionine it becomes the principal methyl donor for DNA methylation, an epigenetic phenomenon associated with cancer [41]. Our findings that high methionine intakes were associated with increased PC risk, may imply that methionine availability at higher than optimal levels may lead to higher bioavailability of S-adenosylmethionine to donate methyl groups to DNA, resulting in DNA hypermethylation of regulatory regions of key genes, including tumor suppressors. For example, hypermethylation of the $\mathrm{CpG}$ promoter sequences of tumor suppressor genes and the GSTP-P1 (glutathione-Stransferase) gene is the most frequent alteration in PC cells and may be associated with prostatic tumorigenesis [42]. Alternatively, higher bioavailable methionine levels could also disrupt the physiologic equilibrium concentrations of S-adenosylmethionine and homocysteine, reducing MTHFR activity $[43,44]$, and thus induce genome-wide hypomethylation, a hallmark of cancer [45].

In addition to higher dietary intakes, methionine can also be regenerated if more circulating 5-Methyl THF is available to remethylate homocysteine to methionine, which may be the case when folate intake is high. However, $>700 \mathrm{mcg} / \mathrm{day}$ of folate intake through diet and supplements have a weak inverse association with PC risk, as reported by others [9], as well as vitamin B6 taken at higher than recommended levels, though these were not seen in the current study. Together, our findings suggest that the driver in the onecarbon metabolism pathway in diseased PC tissues may be methionine and not folate and that previous inconsistent findings in relation to folate intake or in circulation and higher PC risk could be attributed to cohorts in which methionine metabolism is impaired $[5,46]$, though of course this is purely speculative and future larger studies are needed to confirm our findings.

Associations between PC and MTHFR polymorphisms have been mixed [7, 47-51]. We found no evidence for an association between MTHFR gene variants and PC risk, consistent with findings from others [52]. Carriers heterozygous for C677T have a 35\% reduction of MTHFR activity while homozygous C677C carriers have 70\% less MTHFR enzymatic activity [53]. A1298C variants also reduce enzyme activity but to a lesser extent [54]. The C677T variant lies in the catalytic domain at the $\mathrm{NH}_{2}$-terminal region of the protein, while the $\mathrm{A} 1298 \mathrm{C}$ variant lies on the regulatory domain of the MTHFR enzyme, at the $\mathrm{COOH}$-terminal region of the protein, where S-adenosyl-methionine binds, allosterically inhibiting MTHFR [55]. In our study, higher intakes of methionine reported by PC cases may further diminish MTHFR function, which would diminish availability of 5methyl THF to remethylate homocysteine into methionine, which in turn may cause homocysteine accumulation, an effect that has been associated with adenocarcinomas of the breast and ovary $[56,57]$.

Associations between PC risk and higher intakes of folate, vitamin B6, and vitamin B12 were not evident. Although we cannot rule out the possibility that our null associations could have been due to a limited sample size, confirming these findings in a larger study will be important. Ulrich et al. [58] observed an increased colorectal adenoma risk in individuals with lower intakes of folate and B-vitamins, particularly in elder populations (over $60 \mathrm{yr}$ old), suggesting that age may modify the association between folate and cancer risk. Our findings showed that higher intakes of vitamin B12, a cofactor in the reaction of methionine synthase to regenerate methionine from homocysteine [59], was unrelated to PC risk in contrast to a prior study, which showed increased overall PC risk [8]. Together, our results could indicate that methionine metabolism may be impaired in older men who develop PC, and that consuming higher intakes of methionine may aggravate this impairment. This effect could be even more pronounced in individuals carrying the MTHFR A1298C genetic variant. Future research is needed to understand the underlying mechanism for these associations, while more studies are needed to determine whether the effect of high dietary methionine would cause methylation alterations [44].

The main limitation of this study is the small sample size and consequent inability to adequately evaluate the role of common variants in the MTHFR, which limited our ability for stratified analyses by PC grade. Also, the small sample size leads to concerns about type I errors for our significant findings and type II errors for our null observations. In 
this study, African Americans were at higher risk for PC in general, though race/ethnic-specific analyses would benefit by larger sample size. Another limitation is that dietary intake does not account for metabolized nutrients, and circulating levels of nutrients involved in the one-carbon metabolism pathway were not measured and neither were the upstream markers for homocysteine levels. Also, results should be interpreted and framed as "among screeners" since all cases and controls have had a PSA test in the past 12 months; thus it would be uncertain how these findings would relate to populations with lower frequency of PSA testing, since diet quality (and one-carbon nutrient intake) may be related to screening behaviors. However, this study provides early data in support of the provocative hypothesis that excessive intake of one carbon cycle nutrients $[29,30]$ may be associated with increased PC risk. We provide novel evidence for increased $\mathrm{PC}$ risk in relation to high intake of methionine as a function of MTHFR A12986C genotype.

\section{Conclusion}

In summary, our results suggest that higher intakes of methionine, presumably through higher protein consumption, is associated with increased PC risk, regardless of grade of lesion, but only in men carrying the polymorphism MTHFR A1298C. These findings remain preliminary and hypothesis generating. Larger studies are required to validate these findings.

\section{Acknowledgments}

This paper was supported in part by Grants from Department of Defense PC060233 and the National Institutes of Health K01, CA104517, S06-GM008049-33, R01CA142983, and R01CA142983-02S1.

\section{References}

[1] J. Ferlay, H. R. Shin, F. Bray, D. Forman, C. Mathers, and D. M. Parkin, "Estimates of worldwide burden of cancer in 2008: GLOBOCAN 2008," International Journal of Cancer, vol. 127, no. 12, pp. 2893-2917, 2010.

[2] H. Grönberg, "Prostate cancer epidemiology," The Lancet, vol. 361, no. 9360, pp. 859-864, 2003.

[3] L. E. Johns and R. S. Houlston, "A systematic review and metaanalysis of familial prostate cancer risk," BJU International, vol. 91, no. 9, pp. 789-794, 2003.

[4] C. Pelucchi, C. Galeone, R. Talamini et al., "Dietary folate and risk of prostate cancer in Italy," Cancer Epidemiology Biomarkers and Prevention, vol. 14, no. 4, pp. 944-948, 2005.

[5] J. C. Figueiredo, M. V. Grau, R. W. Haile et al., "Folic acid and risk of prostate cancer: results from a randomized clinical trial," Journal of the National Cancer Institute, vol. 101, no. 6, pp. 432-435, 2009.

[6] S. J. Weinstein, T. J. Hartman, R. Stolzenberg-Solomon et al., "Null association between prostate cancer and serum folate, vitamin b 6, vitamin b12, and homocysteine," Cancer Epidemiology Biomarkers and Prevention, vol. 12, no. 11, pp. 12711272, 2003.
[7] B. R. Van Guelpen, S. M. Wirén, A. R. J. Bergh, G. Hallmans, P. E. Stattin, and J. Hultdin, "Polymorphisms of methylenetetrahydrofolate reductase and the risk of prostate cancer: a nested case-control study," European Journal of Cancer Prevention, vol. 15, no. 1, pp. 46-50, 2006.

[8] J. Hultdin, B. Van Guelpen, A. Bergh, G. Hallmans, and P. Stattin, "Plasma folate, vitamin B12, and homocysteine and prostate cancer risk: a prospective study," International Journal of Cancer, vol. 113, no. 5, pp. 819-824, 2005.

[9] M. Johansson, P. N. Appleby, N. E. Allen et al., "Circulating concentrations of folate and vitamin B12 in relation to prostate cancer risk: results from the European prospective investigation into cancer and nutrition study," Cancer Epidemiology Biomarkers and Prevention, vol. 17, no. 2, pp. 279285, 2008.

[10] T. Key, P. B. Silcocks, G. K. Davey, P. N. Appleby, and D. T. Bishop, "A case-control study of diet and prostate cancer," British Journal of Cancer, vol. 76, no. 5, pp. 678-687, 1997.

[11] H. D. Vlajinac, J. M. Marinković, M. D. Ilić, and N. I. Kocev, "Diet and prostate cancer: a case-control study," European Journal of Cancer Part A, vol. 33, no. 1, pp. 101-107, 1997.

[12] V. L. Stevens, C. Rodriguez, A. L. Pavluck, M. L. McCullough, M. J. Thun, and E. E. Calle, "Folate nutrition and prostate cancer incidence in a large cohort of US men," American Journal of Epidemiology, vol. 163, no. 11, pp. 989-996, 2006.

[13] S. J. Weinstein, R. Stolzenberg-Solomon, P. Pietinen, P. R. Taylor, J. Virtamo, and D. Albanes, "Dietary factors of one-carbon metabolism and prostate cancer risk," American Journal of Clinical Nutrition, vol. 84, no. 4, pp. 929-935, 2006.

[14] E. Rossi, J. Hung, J. P. Beilby, M. W. Knuiman, M. L. Divitini, and H. Bartholomew, "Folate levels and cancer morbidity and mortality: prospective cohort study from Busselton, Western Australia," Annals of Epidemiology, vol. 16, no. 3, pp. 206-212, 2006.

[15] J. Shannon, E. Phoutrides, A. Palma et al., "Folate intake and prostate cancer risk: a case-control study," Nutrition and Cancer, vol. 61, no. 5, pp. 617-628, 2009.

[16] S. J. Duthie, "Folic acid deficiency and cancer: mechanisms of DNA instability," British Medical Bulletin, vol. 55, no. 3, pp. 578-592, 1999.

[17] M. Fenech, "The role of folic acid and Vitamin B12 in genomic stability of human cells," Mutation Research, vol. 475, no. 1-2, pp. 57-67, 2001.

[18] B. T. Heijmans, J. M. A. Boer, H. E. D. Suchiman et al., "A common variant of the methylenetetrahydrofolate reductase gene (1p36) is associated with an increased risk of cancer," Cancer Research, vol. 63, no. 6, pp. 1249-1253, 2003.

[19] S. J. Duthie, G. Horgan, B. de Roos et al., "Blood folate status and expression of proteins involved in immune function, inflammation, and coagulation: biochemical and proteomic changes in the plasma of humans in response to long-term synthetic folic acid supplementation," Journal of Proteome Research, vol. 9, no. 4, pp. 1941-1950, 2010.

[20] P. A. Jones and S. B. Baylin, "The fundamental role of epigenetic events in cancer," Nature Reviews Genetics, vol. 3, no. 6, pp. 415-428, 2002.

[21] T. Keku, R. Millikan, K. Worley et al., "5,10-Methylenetetrahydrofolate reductase codon 677 and 1298 polymorphisms and colon cancer in African Americans and whites," Cancer Epidemiology Biomarkers and Prevention, vol. 11, no. 12, pp. 1611-1621, 2002.

[22] M. Lucock, "Science, medicine, and the future: is folic acid the ultimate functional food component for disease prevention?" British Medical Journal, vol. 328, no. 7433, pp. 211-214, 2004. 
[23] J. B. Mason, "Folate, cancer risk, and the Greek god, Proteus: a tale of two chameleons," Nutrition Reviews, vol. 67, no. 4, pp. 206-212, 2009.

[24] S. M. Zhang, W. C. Willett, J. Selhub et al., "Plasma folate, vitamin B6, vitamin B12, homocysteine, and risk of breast cancer," Journal of the National Cancer Institute, vol. 95, no. 5, pp. 373-380, 2003.

[25] U. Ericson, S. Borgquist, M. I. L. Ivarsson et al., "Plasma folate concentrations are positively associated with risk of estrogen receptor $\beta$ negative breast cancer in a Swedish nested case control study," Journal of Nutrition, vol. 140, no. 9, pp. 1661$1668,2010$.

[26] B. F. Cole, J. A. Baron, R. S. Sandler et al., "Folic acid for the prevention of colorectal adenomas: a randomized clinical trial," Journal of the American Medical Association, vol. 297, no. 21, pp. 2351-2359, 2007.

[27] C. M. Pfeiffer, S. P. Caudill, E. W. Gunter, J. Osterloh, and E. J. Sampson, "Biochemical indicators of B vitamin status in the US population after folic acid fortification: results from the National Health and Nutrition Examination Survey 19992000," American Journal of Clinical Nutrition, vol. 82, no. 2, pp. 442-450, 2005.

[28] E. A. Yetley, C. M. Pfeiffer, K. W. Phinney et al., "Biomarkers of folate status in NHANES: a roundtable summary1-6," American Journal of Clinical Nutrition, vol. 94, no. 1, pp. 303S312S, 2011.

[29] C. M. Ulrich, J. D. Potter, and N. Ulrich, "Folate supplementation: too much of a good thing?" Cancer Epidemiology Biomarkers and Prevention, vol. 15, no. 2, pp. 189-193, 2006.

[30] A. D. Smith, Y. I. Kim, and H. Refsum, "Is folic acid good for everyone?" American Journal of Clinical Nutrition, vol. 87, no. 3, pp. 517-533, 2008.

[31] J. B. Mason, A. Dickstein, P. F. Jacques et al., "A temporal association between folic acid fortification and an increase in colorectal cancer rates may be illuminating important biological principles: a hypothesis," Cancer Epidemiology Biomarkers and Prevention, vol. 16, no. 7, pp. 1325-1329, 2007.

[32] S. M. Collin, C. Metcalfe, L. Zuccolo et al., "Association of folate-pathway gene polymorphisms with the risk of prostate cancer: a population-based nested case-control study, systematic review, and meta-analysis," Cancer Epidemiology Biomarkers and Prevention, vol. 18, no. 9, pp. 2528-2539, 2009.

[33] J. A. Antonelli, L. W. Jones, L. L. Bañez et al., "Exercise and prostate cancer risk in a cohort of veterans undergoing prostate needle biopsy," Journal of Urology, vol. 182, no. 5, pp. 2226-2231, 2009.

[34] C. D. Williams, B. M. Whitley, C. Hoyo et al., "A high ratio of dietary n-6/n-3 polyunsaturated fatty acids is associated with increased risk of prostate cancer," Nutrition Research, vol. 31, no. 1, pp. 1-8, 2011.

[35] J. A. Roebuck Jr., Anthropometric Methods: Designing To Fit the Human Body, Human Factor and Ergonomics Society, Santa Monica, Calif, USA, 1995.

[36] W. C. Willet, L. Sampson, M. J. Stampfer et al., "Reproducibility and validity of a semiquantitative food frequency questionnaire," American Journal of Epidemiology, vol. 122, no. 1, pp. 51-65, 1985.

[37] C. F. Adams, Nutritive Value of American Foods, vol. 456, United States Department of Agriculture, 1975.

[38] R. M. Feeley, P. E. Criver, and B. K. Watt, "Cholesterol content of foods," Journal of the American Dietetic Association, vol. 61, no. 2, pp. 134-149, 1972.
[39] P. J. McLaughlin and J. L. Weihrauch, "Vitamin E content of foods," Journal of the American Dietetic Association, vol. 75, no. 6, pp. 647-665, 1979.

[40] S. Bettuzzi, M. Brausi, F. Rizzi, G. Castagnetti, G. Peracchia, and A. Corti, "Chemoprevention of human prostate cancer by oral administration of green tea catechins in volunteers with high-grade prostate intraepithelial neoplasia: a preliminary report from a one-year proof-of-principle study," Cancer Research, vol. 66, no. 2, pp. 1234-1240, 2006.

[41] P. M. Das and R. Singal, "DNA methylation and cancer," Journal of Clinical Oncology, vol. 22, no. 22, pp. 4632-4642, 2004.

[42] W. H. Lee, W. B. Isaacs, G. Steven Bova, and W. G. Nelson, "CG island methylation changes near the GSTP1 gene in prostatic carcinoma cells detected using the polymerase chain reaction: A new prostate cancer biomarker," Cancer Epidemiology Biomarkers and Prevention, vol. 6, no. 6, pp. 443-450, 1997.

[43] X. Shan, L. Wang, R. Hoffmaster, and W. D. Kruger, "Functional characterization of human methylenetetrahydrofolate reductase in Saccharomyces cerevisiae," Journal of Biological Chemistry, vol. 274, no. 46, pp. 32613-32618, 1999.

[44] R. A. Waterland, "Assessing the effects of high methionine intake on DNA methylation," Journal of Nutrition, vol. 136, no. 6, 2006.

[45] A. P. Feinberg, R. Ohlsson, and S. Henikoff, "The epigenetic progenitor origin of human cancer," Nature Reviews Genetics, vol. 7, no. 1, pp. 21-33, 2006.

[46] J. J. Tomaszewski, J. L. Cummings, A. V. Parwani et al., "Increased cancer cell proliferation in prostate cancer patients with high levels of serum folate," Prostate, vol. 71, no. 12, pp. 1287-1293, 2011.

[47] C. Marchal, M. Redondo, A. Reyes-Engel et al., "Association between polymorphisms of folate-metabolizing enzymes and risk of prostate cancer," European Journal of Surgical Oncology, vol. 34, no. 7, pp. 805-810, 2008.

[48] J. Chen, J. Ma, M. J. Stampfer, C. Palomeque, J. Selhub, and D. J. Hunter, "Linkage disequilibrium between the $677 \mathrm{C} \rightarrow \mathrm{t}$ and $1298 \mathrm{~A} \rightarrow$ C polymorphisms in human methylenetetrahydrofolate reductase gene and their contributions to risk of colorectal cancer," Pharmacogenetics, vol. 12, no. 4, pp. 339-342, 2002.

[49] S. Ogino and R. B. Wilson, "Genotype and haplotype distributions of MTHFR677C $\rightarrow$ T and 1298A $\rightarrow$ C single nucleotide polymorphisms: a meta-analysis," Journal of Human Genetics, vol. 48, no. 1, pp. 1-7, 2003.

[50] N. Rosenberg, M. Murata, Y. Ikeda, O. Opare-Sem, E. Geffen, and U. Seligsohn, "The frequent 5, 10-methylenetetrahydrofolate reductase C677T polymorphism is associated with a common haplotype in Whites, Japanese, and Africans,", American Journal of Human Genetics, vol. 70, no. 3, pp. 758762, 2002.

[51] M. S. Cicek, N. L. Nock, L. Li, D. V. Conti, G. Casey, and J. S. Witte, "Relationship between methylenetetrahydrofolate reductase C677T and A1298C genotypes and haplotypes and prostate cancer risk and aggressiveness," Cancer Epidemiology, Biomarkers \& Prevention, vol. 13, no. 8, pp. 1331-1336, 2004.

[52] V. L. Stevens, C. Rodriguez, J. Sun, J. T. Talbot, M. J. Thun, and E. E. Calle, "No association of SNPs in one-carbon metabolism genes with prostate cancer risk," Cancer Epidemiology, Biomarkers \& Prevention, vol. 17, no. 12, pp. 3612-3614, 2008.

[53] P. Frost, H. J. Blom, P. Gollete, C. A. Sephhard, and R. G. Matthews, "A candidate genetic risk factor for vascular disease," Nature Genetics, vol. 10, no. 24, pp. 111-113, 1995.

[54] N. M. Van der Put, F. Gabreels, E. M. Stevens et al., "A second common mutation in the methylenetetrahydrofolate 
reductase gene: an additional risk factor for neural-tube defect?" American Journal of Human Genetics, vol. 62, no. 5, pp. 1044-1051, 1998.

[55] J. Summer, D. A. Jencks, S. Khani, and R. G. Matthews, "Photoaffinity labeling of methylnetetrahydrofolate reductase with 8-azido-S-adenosylmethionine," Journal of Biological Chemistry, vol. 261, no. 17, pp. 7697-7700, 1986.

[56] G. Corona, G. Toffoli, M. Fabris et al., "Homocysteine accumulation in human ovarian carcinoma ascetic/cystic fluids possibly caused by metabolic alteration of the methionine cycle in , ovarian carcinoma cells," European Journal of Cancer, vol. 33, no. 8, pp. 1284-1290, 1997.

[57] J. Lin, I. M. Lee, Y. Song et al., "Plasma homocysteine and cysteine and risk of breast cancer in women," Cancer Research, vol. 70, no. 6, pp. 2397-2405, 2010.

[58] C. M. Ulrich, E. Kampman, J. Bigler et al., "Colorectal adenomas and the C677T MTHFR polymorphism: evidence for gene-environment interaction?" Cancer Epidemiology, Biomarkers \& Prevention, vol. 8, no. 8, pp. 659-668, 1999.

[59] H. Refsum, P. M. Ueland, O. Nygard, and S. E. Vollset, "Homocysteine and cardiovascular disease," Annual Reviews, vol. 49, pp. 31-62, 1998. 


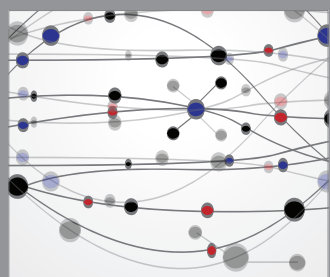

The Scientific World Journal
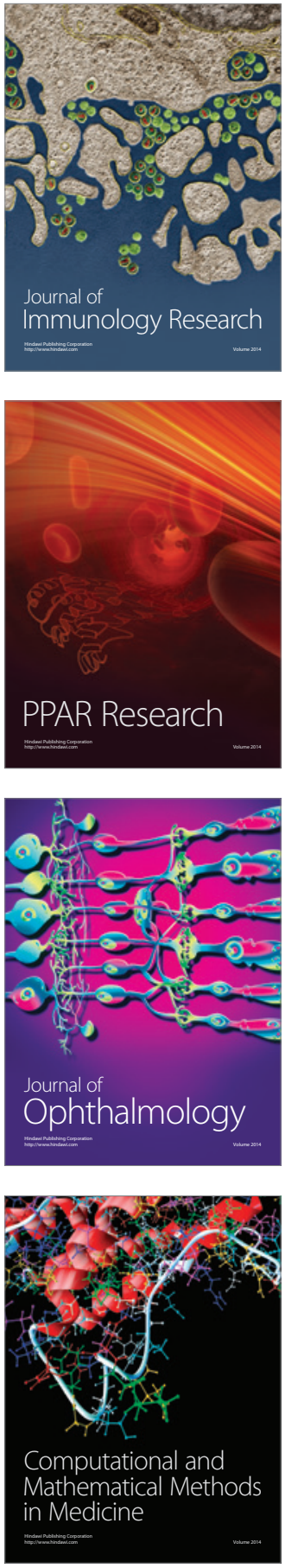

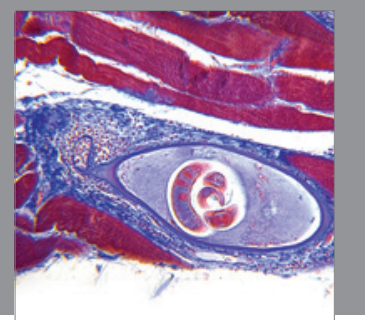

Gastroenterology

Research and Practice
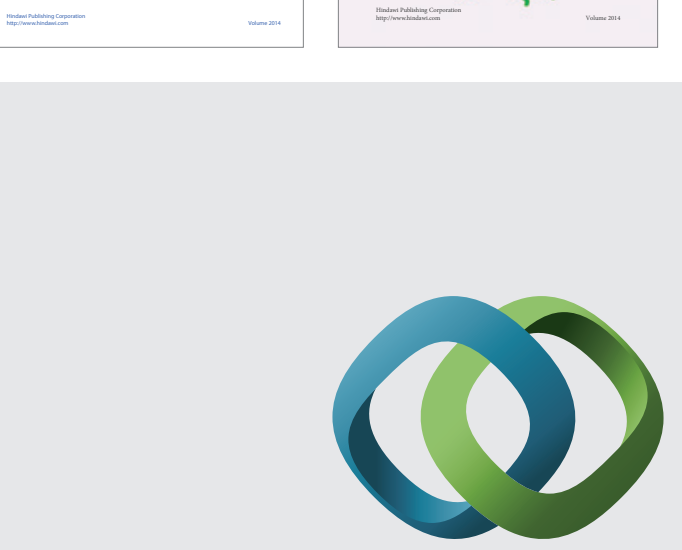

\section{Hindawi}

Submit your manuscripts at

http://www.hindawi.com
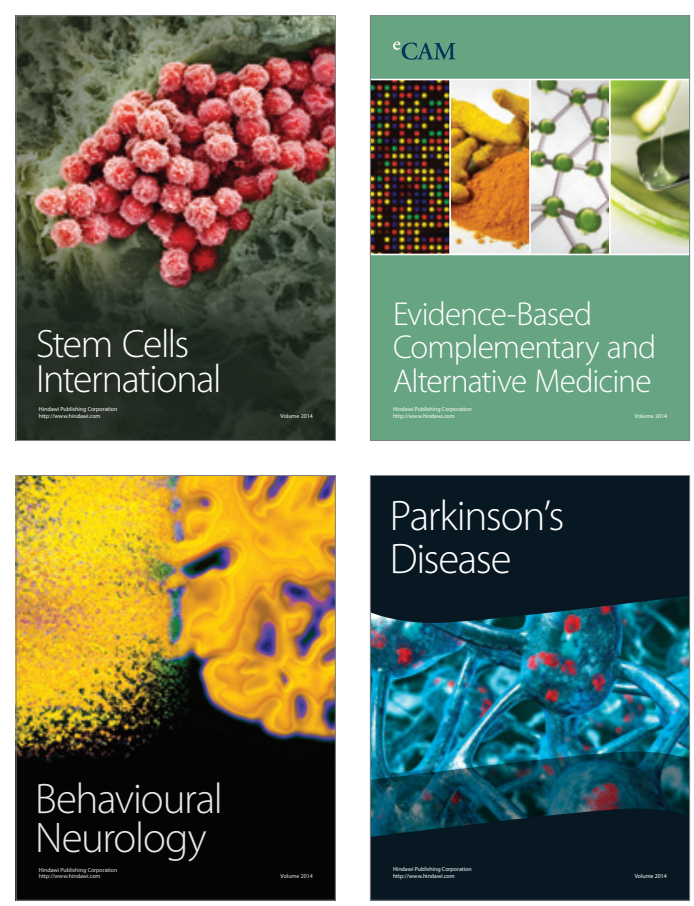

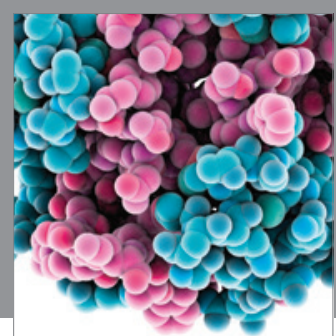

Journal of
Diabetes Research

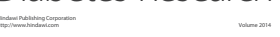

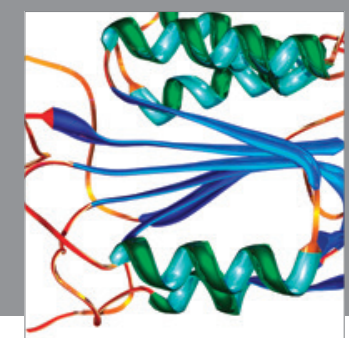

Disease Markers
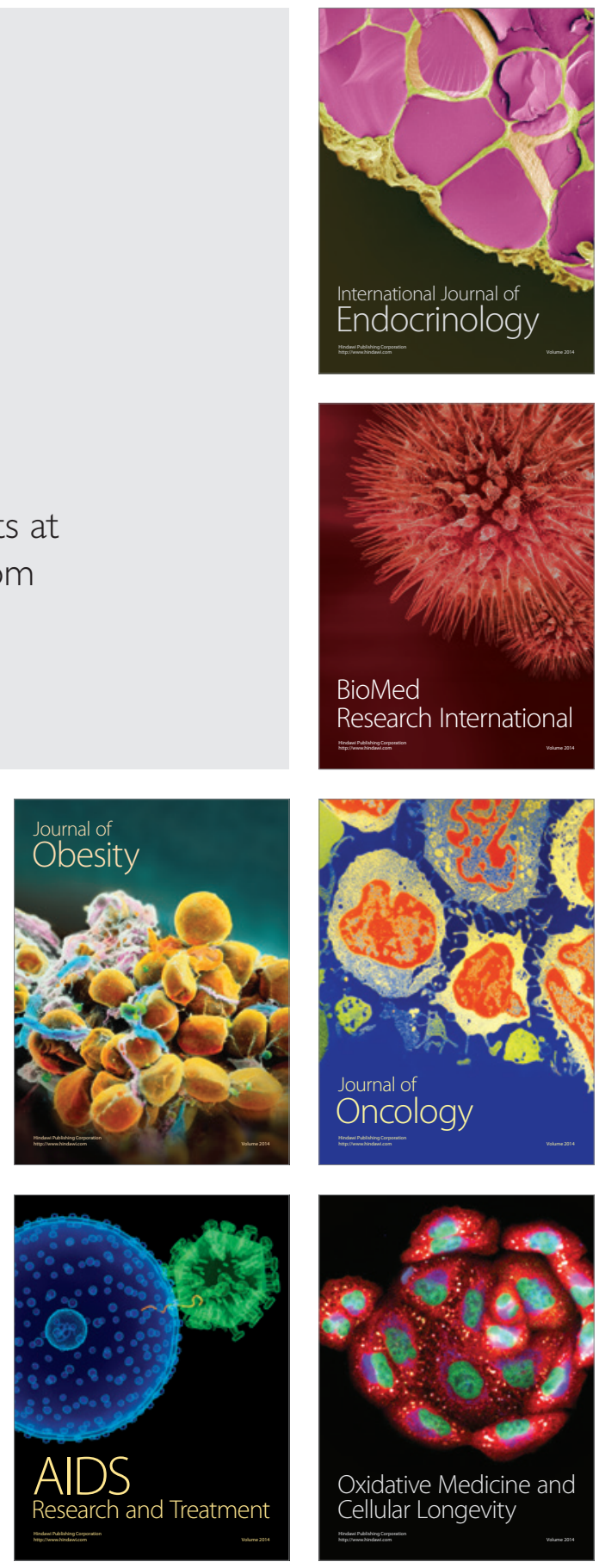